\title{
Erratum zu: Alte und neue soziale Ungleichheiten bei Berufsaufgabe und Rentenübergang
}

\section{Ergebnisse des EXTEND-Projektes}

\section{Erratum zu: \\ G. Naegele und M. Hess (Hrsg.), Alte und neue soziale Ungleichheiten bei Berufsaufgabe und Rentenübergang, Dortmunder Beiträge zur Sozialforschung, https://doi.org/10.1007/978-3-658-31663-1}

Ein technischer Fehler im Produktionsablauf hat dazu geführt, dass das Buch zunächst mit 2021 als Copyright Jahr veröffentlicht wurde. Das Copyright Jahr ist 2020. Dies wurde nachträglich korrigiert.

Die aktualisierte Version des Buches finden Sie unter https://doi.org/10.1007/978-3-658-31663-1 